\title{
Learning history through porcelains
}

\section{Chinese porcelain bowl exports in the second half of the Ming Dynasty and the shift in domestic production of earthenware in Southeast Asia}

\section{Supakorn Yuenyongwannchot}

From The School of anti-aging and regenerative medicine,

Mae Fah Luang university, Chiang Rai, Thailand

Address correspondence to S.Y. (e-mail: pingnok007@hotmail.com)

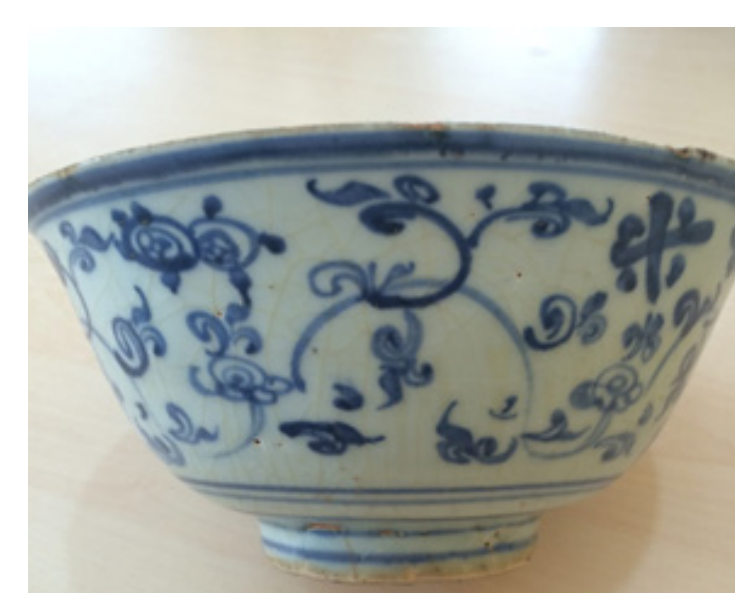

Figure 1. (A) Side view

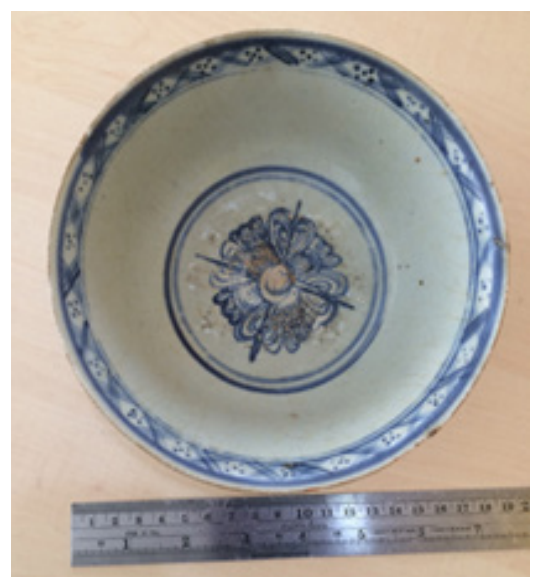

(B) Top view

The blue and white porcelain bowls patterned and decorated as in Figure 1 could be commonly seen in museums and antique shops in Southeast Asian countries. A common characteristic was the approximately 6 inched diameter with the narrow lower part and the slightly expanded rim, adorned with blue color under glaze. The decorative pattern might slightly vary from one piece to another. For example, the porcelain in Figure 1 was bought from an Indonesian antique seller who asserted that it was discovered in a river. The outer part was painted with flower scroll design, with the blue lines encircled the outer lower part and the rim of the bowl. The inner part of the bowl was adorned with Vajara pattern 
inside the circle at the base in which the inner rim was adorned with the alternating pattern of crosses and dots. The evenly spread and thin matte which revealed its milky white porcelain clearly indicated that it was sunken under in the river for hundreds of years. A bowl with the mentioned characteristics is believed to be a product in the Ming Dynasty during the reign of the Hongzhi Emperor (1487-1505AD).

According to the timeline in Figure 2, at the time, the present-day Vietnam was ruled by Champa and Dai Viet Empires. Khmer Empire under its dark age was invaded by flourishing Siamese Ayuthaya Kingdom. At the same time, it was the first half of Burmese Empire and latter half of Majapahit Empire that ruled over the land of present day Indonesia before she entered the period in which islands of Indonesia were overwhelmingly filled with fleets from Spain and Portugal for hundreds of years.

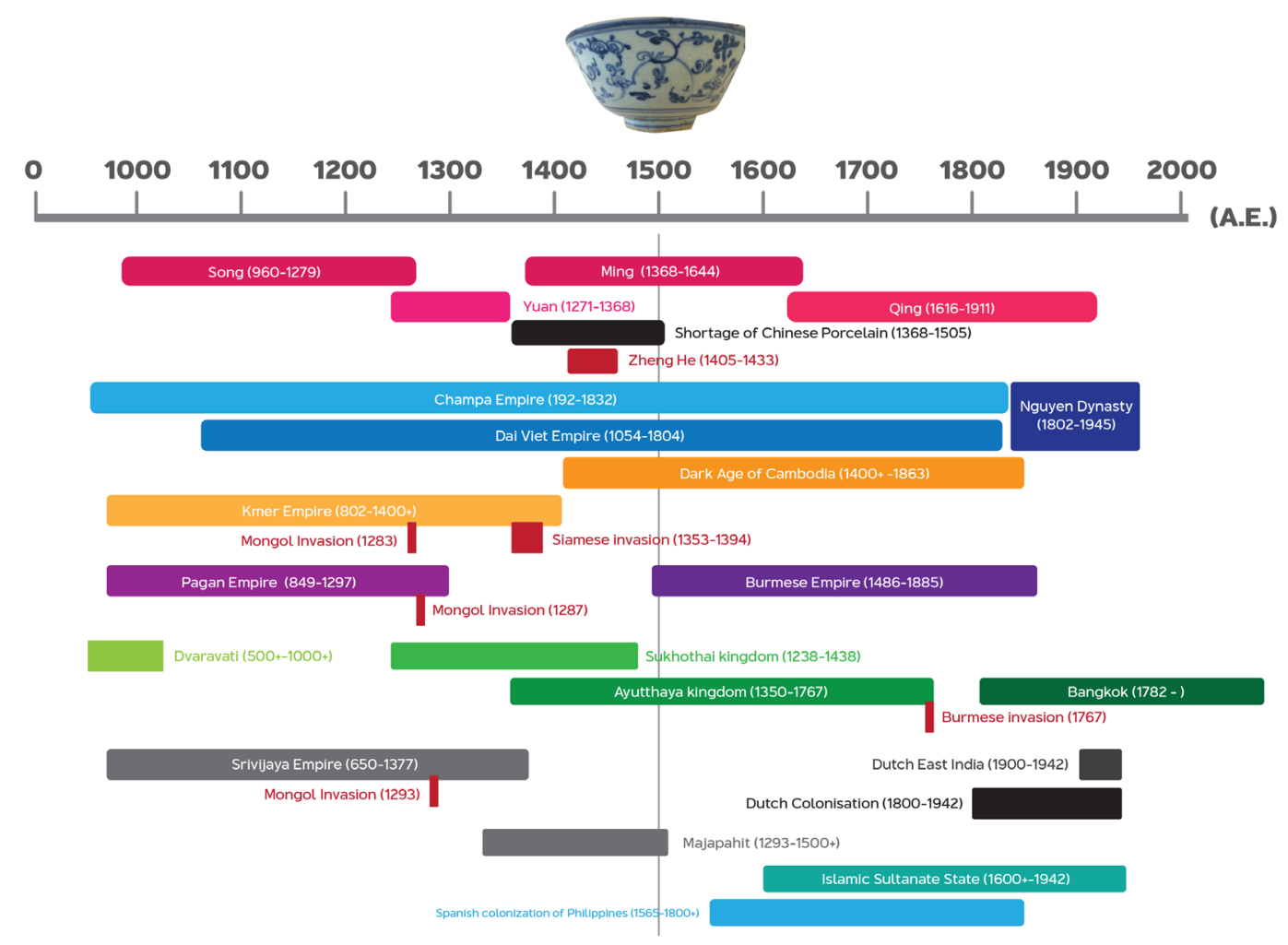

Figure 2: Timeline showing the dynastic rules In China and Southeast Asian empires. 
The porcelain bowl market in Southeast Asia at that time was rapidly expanding and porcelain bowls along with the utensils were in a strong demand. They were mainly used as utensils for consumption by their virtue of being strong but light in weight while also not leaving undesirable smell and residue after the usage. Furthermore, the taste of food was not distorted by porcelain bowls. That is not all, some were even used in religious ceremonies as they were regarded as rare object owing to the improbability of being produced in Southeast Asia. For this reason, porcelain bowls also served as the status symbol of the affluent at that era as well as provided beauty with their intricately-shaped forms and luster coloration. The flourishing production, thriving trade and enormous demands can be apparently observed in the evidence of shipwreck and discovered kiln sites as shown in Figure 3.

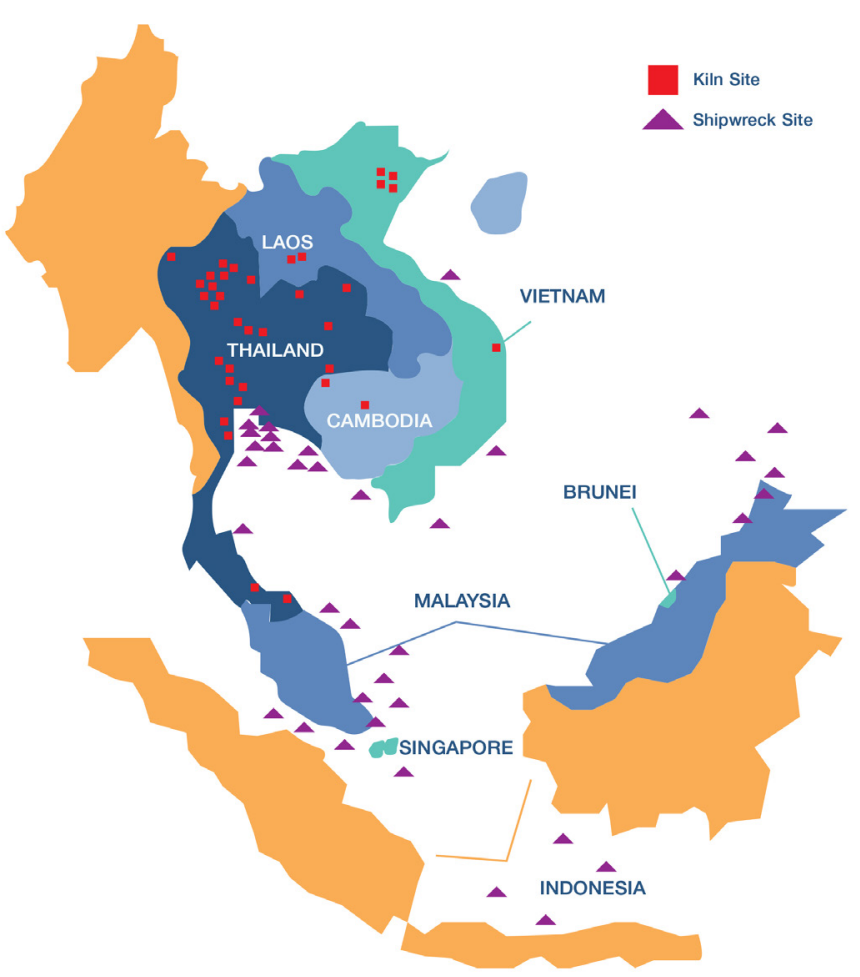

The Kiln sites could be found here and there in Southeast Asia with the highest numbers concentrated in the northern part, running down along the path of the river in the area of the modern day Thailand and sparsely distributed in the modern day Northern Laos and Vietnam. The shipwreck sites were highly concentrated in the Gulf of Thailand, the eastern part of The Malay Peninsula, Straits of Malacca, the Coast of the Philippines and the Southern Coast of Vietnam.

Figure 3. Kiln sites and shipwreck sites [1]. 
The prosperous domestic production of porcelain bowls in Southeast Asia as illustrated by the extensive numbers of shipwreck sites on the map which reached their peak during the beginning of the Ming Dynasty. The reason of the flourishing domestic production was due to stricter control of porcelain exports during the early Ming Dynasty due to the concern over its domestic security. (Porcelains were the largest exports of China which were among the other two most exported items including metal and silk.)

However, during the reign of the Hongzhi Emperor, the export rules of porcelain were no longer tightly regulated and the exports of Chinese porcelains became flourishing again. This caused the domestic production of porcelains in Southeast Asia to gradually close down and finally no longer operate in the reign of the Wanli Emperor (1572-1620 AD).

By carefully looking into porcelain bowls in Figure 1, we can conspicuously acknowledge the reason that this little bowl could led to the decline in domestic kiln sites. Looking in hindsight, around 500 years ago, kilns in Southeast Asia could only be used to produce heavy and thick earthenware which were mostly in a dull single color and lackluster glaze. The arrival of Chinese porcelain exports during the Hongzhi Emperor's reign with its "novelty" and "insurmountable beauty" made monumental changes in the market of bowls and utensils. Despite that, it was not only the novelty of the porcelain exports alone that marked the monumental changes in the market of bowls and utensils in Southeast Asia, but also improved transportation, lower cost and more convenient trading networks that performed as crucial catalyst to be taken into consideration regarding these changes as it's mentioned in the Chronicle of China that at the particular era, there was already a well-established network of Chinese merchants throughout Siam, Indonesia, and Malacca. 


\section{References}

1. Brown RM. The ming gap and shipwreck ceramics in Southeast Asia towards a chronology of Thai trade ware. Bangkok: The Siam Society under Royal Patronage; 2009.

2. Vainker SJ. Chinese pottery and porcelain from prehistory to the present. London: The Trustees of the Brithish Museum; 1995.

3. Medley M. The Chinese potter: a practical history of Chinese ceramics. London: Phaidon Press Limited; 1999. 